\title{
INTERSEÇÕES NA GESTÃO DA ACESSIBILIDADE NA EDUCAÇÃO BÁSICA E NO ENSINO SUPERIOR: UM ENSAIO OMNILÉTIÇO
}

\author{
INTERSECCIONES EN LA GESTIÓN DE LA ACCESIBILIDAD EN LA \\ EDUCACIÓN BÁSICA Y LA EDUCACIÓN SUPERIOR: UN ENSAYO \\ OMNILECTICO
}

\author{
INTERSECTIONS IN THE MANAGEMENT OF ACCESSIBILITY IN BASIC \\ EDUCATION AND HIGHER EDUCATION: AN OMNILETICAL REFLECTION
}

\author{
Mônica Pereira dos SANTOS ${ }^{1}$ \\ Sandra Cordeiro de MELO $^{2}$
}

\begin{abstract}
RESUMO: Este artigo, de caráter ensaístico, objetiva discutir criticamente a acessibilidade em duas instituições federais de ensino: uma de nível superior e outra de nível básico. Argumentamos que o comprometimento da gestão institucional faz toda a diferença quando se trata de acessibilidade. Resguardadas as especificidades de cada nível de ensino, a partir dos casos narrados tecemos comparações a respeito dos encaminhamentos dados por cada instituição e concluímos, a partir de uma análise omnilética, que o sucesso de iniciativas de acessibilidade - e, consequentemente, de inclusão, no caso do presente artigo, de pessoas com deficiência -, está intimamente vinculado ao compromisso e coerência que a gestão assume em promover acessibilidade e inclusão para todos como uma premissa institucional.
\end{abstract}

PALAVRAS-CHAVE: Gestão. Educação básica e ensino superior. Acessibilidade e inclusão. Pessoa com deficiência. Perspectiva omnilética.

RESUMEN: Este artículo, de característica ensayística, tiene la intención de discutir críticamente el estado actual de la accesibilidad en dos instituciones educativas federales: uno del nivel superior y el otro del nivel básico. Sostenemos que el compromiso de la gestión institucional marca la diferencia cuando se trata de accesibilidad. Dadas las especificidades de cada nivel de educación, de los casos narrados tejemos comparaciones con las referencias a las tomadas de decisión por cada institución y concluimos, a partir de una análisis omnilectica, que el éxito de las iniciativas de accesibilidad - y, en consecuencia, la inclusión, en el caso de este artículo, de personas con discapacidad, están íntimamente ligados al compromiso y la coherencia que asume la gestión en la promoción de la accesibilidad y la inclusión para todos como premisa institucional.

\footnotetext{
${ }^{1}$ Universidade Federal do Rio de Janeiro (UFRJ), Rio de Janeiro - RJ - Brasil. Docente e Pesquisadora do Departamento de Fundamentos da Educação. ORCID: https://orcid.org/0000-0002-7057-7804. E-mail: monicapes@gmail.com

${ }^{2}$ Universidade Federal do Rio de Janeiro (UFRJ), Rio de Janeiro - RJ - Brasil. Docente e Pesquisadora do Departamento de Fundamentos da Educação. ORCID: https://orcid.org/0000-0002-8437-1671. E-mail: sandracmello@gmail.com
} 
PALABRAS CLAVE: Gestión. Educación básica y Educación superior. Accesibilidad y inclusión. Persona discapacitada. Perspectiva omnilectica.

ABSTRACT: This essay intends to critically discuss the current state of accessibility in two federal educational institutions: one belonging to higher education level and the other to the basic education level. We argue that the commitment of institutional management makes all the difference when it comes to accessibility. Given the specificities of each level of education, from the reported cases we draw comparisons regarding the referrals taken by each institution and conclude, from an omniletical analysis, that the success of accessibility initiatives - and, consequently, the inclusion of people with disabilities, in the case of this article -, is intimately linked to the commitment and coherence that management assumes in promoting accessibility and inclusion for all as an institutional premise.

KEYWORDS: Educational management. Basic and higher education. Accessibility and inclusion. Disabled person. Omniletical perspective.

\section{Introdução}

Os temas da acessibilidade e inclusão de pessoas com deficiência têm constituído pauta contundente de discussões na Educação Básica desde os anos 90. A partir, especialmente, de 2008, no plano internacional; e de 2015, no plano nacional, tais temas também têm constituído pauta nas agendas da Educação Superior.

No que tange à Educação Básica, podemos destacar como documento disparador desta pauta em nível nacional a Declaração Mundial sobre Educação para Todos (UNESCO, 1990), que em seu item 3.5 menciona especificamente o grupo de pessoas com deficiência como tendo direito de acesso e permanência à/na educação.

$\mathrm{Na}$ esfera nacional, podemos traçar o momento do "disparo" inicial à LDB Lei de Diretrizes e Bases da Educação Nacional 9394/96 (BRASIL, 1996), cujo Capítulo 5 é inteiramente dedicado à temática da Educação Especial, temática essa profundamente afim aos temas da acessibilidade e de inclusão.

Com relação à Educação Superior, no plano internacional é possível destacarmos como documento iniciador a Declaração Mundial de Educação Superior (UNESCO, 1998), que em seu artigo $3^{\circ}$ menciona a importância de se facilitar o acesso à universidade por grupos vulneráveis, dentre eles o das pessoas com deficiência. $\mathrm{O}$ artigo também menciona a relevância de se prover suporte adequado para que tais grupos permaneçam na universidade e finalizem seus estudos com sucesso. 
No âmbito nacional, destacamos o Plano Nacional de Educação, Lei $\mathrm{N}^{\circ}$ 13.005/2014 (BRASIL, 2014), cuja Meta 12 refere-se à necessidade de ampliação do alunado da educação superior. Na sua quinta estratégia, é destacada a urgência em se ampliar as políticas institucionais de inclusão e de assistência estudantil, tendo em vista a redução das desigualdades e a ampliação do acesso e permanência, com sucesso, dos grupos estudantis em situação de vulnerabilidade, pessoas com deficiência aí incluídas.

Assim, o termo acessibilidade tem um caráter mais específico no sentido de vincular-se a certos grupos ou pessoas (em geral, pessoas com deficiência, mobilidade reduzida e idosos). Já o termo inclusão é compreendido como sendo um princípio basilar, estreitamente vinculado ao ideário de Direitos Humanos e, como tal, dirige-se a todos, sem exceção ou especificação. Isto significa afirmar, em uma aparente contradição, que para que os direitos sejam efetivamente garantidos a todos, é preciso que se os aborde com diferenciação.

Neste sentido, falar de inclusão é pensar em todos e agir para cada um, enquanto que, complementarmente, falar em acessibilidade é pensar em cada um com a intenção de agir para todos. Ambos implicam, em última instância, no esforço de se desenvolver culturas, políticas e práticas de justiça social, justamente porque o pensar é para promover justiça para um coletivo, mas o fazer que garante isso é o não padronizado.

Convém, aqui, uma breve digressão para esclarecer que nossa perspectiva, a Omnilética, constitui-se, epistemologicamente, no desenvolvimento de um olhar que parte da premissa de que a vida humana e social pode ser compreendida a partir de 5 dimensões: cultural, política, prática, dialética e complexa. As três primeiras dimensões são fundamentadas nas obras de Booth e Ainscow (2002, 2006, 2012, 2016), que associam culturas ao desenvolvimento de valores de inclusão; políticas à organização administrativa de uma instituição em apoio à inclusão; e prática ao planejamento e execução curriculares. Na omnilética, ampliamos a ideia de política para incorporar, também, as normativas e preceitos legais de nível nacional. Regional, local e institucional. Ampliamos, ainda, as práticas, para extrapolar a execução do currículo para compreender, também, qualquer prática social existente dentro das instituições educacionais, inclusive as de violência.

A dimensão dialética, na omnilética, inspira-se em Lukács (2015) ao trabalhar o aspecto de totalidade da dialética, assim como a noção de sua organização em complexos de complexos. Por fim, a dimensão da complexidade, oriunda dos trabalhos de Morin (2008), é incorporada à omnilética no que ela traz de relação com o princípio 
da incerteza e com a potenciação e abertura da visão sobre os problemas sociais como portas ainda não abertas para que se chegue a outras novas situações (sempre provisórias, dada a incerteza das coisas) que possam servir de "saídas", soluções ou novas portas a serem exploradas, ressignificando continuamente a realidade.

Realizado este esclarecimento sobre nosso entendimento de acessibilidade, inclusão e a perspectiva omnilética, e retomando nosso raciocínio inicial sobre estes temas na Educação Básica e na Superior, podemos supor que a promoção da acessibilidade e os movimentos de inclusão em cada nível de ensino apresentem semelhanças e diferenças nos mais variados aspectos e dependendo de cada instituição. O trato com o "todos" e o "cada um" mencionados acima torna praticamente impossível criarmos critérios que nos permitam uma comparação completamente confiável entre as realidades da estrutura da educação brasileira e suas instituições dos variados níveis.

Mesmo assim, algumas questões permanecem: que interseções podem ser traçadas entre estes dois níveis de educação? Qual seria a relevância de se levar a cabo tal empreitada? O que tais interseções poderiam nos ensinar, se identificadas, em termos de promoção de inclusão e de acessibilidade?

Tendo tais questões em mente, organizamos nosso artigo em 4 seções. Na primeira, falaremos sobre a experiência na educação básica. Na segunda, descreveremos uma experiência na educação superior. Em seguida, realizaremos um ensaio analítico que procurará responder às questões colocadas neste artigo para, ao final, chegarmos a algumas conclusões e, quem sabe mesmo, sugestões sobre o tema da promoção de acessibilidade e inclusão no que tange à gestão institucional.

Em uma última palavra introdutória, queremos esclarecer o caráter ensaístico artigo, ou seja, incipientemente reflexivo. Como diz Meneghetti (2011):

[...] o ensaio valoriza aspectos relacionados às mudanças qualitativas que ocorrem nos objetos ou fenômenos analisados pelos ensaístas. [...]. A forma como o ensaísta experimenta, especula e vivencia o objeto só se torna possível na compreensão qualitativa dele. Abre-se mão das simples classificações e quantificações que possam criar categorias generalizáveis para o entendimento humano compartilhado. [...] Sua lógica foge à racionalidade instrumental ou à calculabilidade do mundo moderno (p. 322).

Desta forma, o texto ensaístico não se fundamenta em uma pesquisa, mas em leituras e vivências que, cuidadosamente observadas, servem de base para as questões que lançadas e, futuramente, quiçá, seja também norteador de uma pesquisa. 


\section{Sobre a escola federal da educação básica}

A escola que relatamos neste artigo foi fundada em 04 de abril de 1960 com o objetivo de educar/formar os filhos de civis e militares da Força militar à qual pertence. Atualmente atende a 1.100 alunos, nos turnos da manhã e da tarde, do $1^{\circ}$ ano do Ensino Fundamental até o $3^{\circ}$ ano do Ensino Médio, dos quais a maior parte dos discentes são dependentes de civis. Oferece ainda cursos preparatórios para o Exame Nacional do Ensino Médio (ENEM), para alunos civis e oriundos de instituições militares e, ainda, o curso Técnico de Enfermagem. De acordo com o Parecer 829/81, que trata sobre o regime de subordinação da escola, ela se designa como de ensino militar, portanto excluída do âmbito do sistema civil. Isto significa que ela é regulada por lei especial, que a situa fora do alcance do Ministério da Educação e, por consequência, das Secretarias e dos Conselhos Estaduais de Educação. O artigo 83 da Lei de Diretrizes e Bases da Educação (Lei 9394/96) ratifica que o ensino militar é regulado em lei específica, admitida a equivalência de estudos, de acordo com as normas fixadas pelos sistemas de ensino. A escola de nosso artigo conta com 132 professores, dentre estes, servidores públicos federais, militares de carreira, militares temporários e militares aposentados.

\section{O projeto tirando dúvidas e sanando dívidas}

De acordo com Lima e Souza, em artigo sobre a referida escola:

em 2013, o corpo docente [...], em conselho de classe final, apontou um número expressivo de alunos reprovados no $9^{\circ}$ ano, os quais apresentavam sérias dificuldades de aprendizagem e defasagem idade/série. Tendo em vista a real situação e a certeza de que os métodos que estavam sendo aplicados há anos não estavam resolvendo efetivamente os problemas referentes à aprendizagem desses alunos, dois professores propuseram à direção do colégio, um projeto de ensino diferenciado (2018, p. 148).

O projeto propunha abrir uma turma de nono ano, com os alunos de piores rendimentos e com as maiores defasagens idade/série e tinha por objetivo desenvolver formas alternativas de ensino focadas no grupo de alunos candidatos à reprovação e ao posterior jubilamento. A orientação do projeto foi a de fortalecer o ensino nas áreas da 
Língua Portuguesa e Matemática, além das disciplinas obrigatórias, e ainda inserir no currículo disciplinas como Filosofia, Sociologia e Música. A ideia era a de que:

se o aluno souber ler e escrever de modo a compreender e transmitir com clareza e objetividade o que leu e escreveu, além de realizar com propriedade as operações matemáticas no conjunto dos números reais, acreditar-se-ia que ele poderia compreender os demais conteúdos curriculares (LIMA; SOUZA, 2018, p.149).

As autoras citadas relatam que "as primeiras semanas foram difíceis, os alunos não aceitavam fazer parte de um projeto que estava sendo rotulado pela escola como o 'projeto dos repetentes"'. Segundo elas, os professores foram entendendo que junto com a dificuldade de aprender estava a questão da autoestima. (LIMA; SOUZA, 2018, p. 149).

Atualmente, o projeto ampliou o seu campo de atuação com mais duas turmas: além daquela do nono ano do ensino fundamental, uma do primeiro ano e uma do segundo ano do ensino médio foram iniciadas. O objetivo do projeto é o de recuperar os estudantes nas atividades escolares, e assim fazendo, trabalhar em prol da elevação da autoestima destes, visando uma maior inserção social de alunos que se sentiam excluídos. Um exemplo disso é o caso de uma aluna, de 21 anos, da turma de segundo ano do ensino médio que apresenta deficiência intelectual. De acordo com os documentos coletados pela escola, como histórico escolar e avaliação psicológica, a aluna concluiu o ensino fundamental pela modalidade supletiva e apresenta muitas dificuldades de aprendizado, que remontam ao seu processo de alfabetização, pensamento abstrato e postura infantilizada.

Para fins desta análise, cumpre destacar os esforços da equipe de professores do projeto em contribuir para o desenvolvimento cognitivo e social da aluna individualmente e dos demais colegas como um coletivo. Pesquisas sobre cada caso, o olhar acurado sobre as dúvidas e ainda reuniões com um grupo de pesquisa da Universidade Federal do Rio de Janeiro para discussão sobre suas estratégias didáticas trabalhadas, compõem um esforço em equipe para tirar as dúvidas dos alunos e recuperá-los da melhor forma possível. Acreditamos que o compromisso da gestão do colégio, permitindo a criação do projeto, e dos professores participantes, fazem a diferença no desenvolvimento de alunos que, de outra forma, estariam fora do processo educativo. 


\section{Ações que fazem a diferença}

Em que pese a criação de três turmas fora do contexto regular do colégio, com finalidades específicas de apoio aos estudantes com dificuldade de aprendizagem, mas que em sua própria estrutura os separaria dos colegas de mesmo ano, o projeto Tirando Dúvidas e Sanando Dívidas ${ }^{3}$ representou, na escola, o espaço de atenção no qual foram ressignificados conceitos referentes à escolarização, à aprendizagem, à participação, ao desenvolvimento, ao ensino. Os professores participantes foram sensibilizados para as histórias escolares dos alunos, para as suas dificuldades de aprendizagem. Além disso, a eles foi dado um tempo mais flexível para trabalhar com os alunos, pois o conteúdo que não era concluído no $9^{\circ}$ ano, poderia ser desenvolvido nos anos seguintes.

O currículo foi ampliado, incluindo as disciplinas de Língua Espanhola, Biologia, Sociologia e Filosofia e aumentando a carga horária das disciplinas de Língua Portuguesa e Matemática em dois tempos semanais. Foram oferecidas atividades extras no contraturno como aulas de reforço e oficinas, nas quais a participação do aluno era de fundamental importância. Em consonância com o projeto, a escola designou uma orientadora pedagógica para acompanhar as turmas de forma exclusiva, fazendo a ponte entre o aluno, o professor e a família, além de limitar em 20 o número de alunos por turma.

No intuito de conhecer as especificidades de cada aluno e o trabalho desenvolvido pelos professores do projeto, foram realizadas reuniões semanais de conversas, trocas de experiências e estudos. Estes encontros serviram também de apoio mútuo ao trabalho docente. No projeto, buscando trabalhar a autonomia, o reconhecimento próprio e a autoestima dos alunos, além dos conteúdos escolares, os professores também foram tocados. Foram percebidos como atores importantes e fundamentais na vida daqueles alunos.

Omnileticamente, podemos dizer que esta instituição vive suas contradições (como qualquer outra), o que aponta para o caráter dialético desta totalidade, ao mesmo tempo em que se vê envolta pela complexidade, por estar sempre buscando novas alternativas. Neste movimento, desenvolve, ainda que sem perceber, novas culturas, políticas e práticas.

${ }^{3}$ Este projeto foi desenvolvido internamente na escola e não foi publicado. 


\section{Sobre a universidade federal}

A universidade aqui narrada completará, em 2020, no dia 7 de setembro, um século de existência. Convém registrar que seu início se deu de forma peculiar: não como uma universidade em si, mas a partir da junção, em universidade, de diferentes Unidades que já existiam. Eram elas: a Faculdade de Medicina, a Escola Politécnica e a Faculdade de Direito. Sua expansão se deu a partir de 1930 e hoje ela é composta por 42.549 alunos matriculados ativos ${ }^{4}$ em 176 cursos de graduação que funcionam em turnos matutinos, vespertinos e noturnos. Na pós-graduação, a universidade possui ${ }^{5} 130$ cursos de mestrados acadêmico e profissional e 94 cursos de doutorado, além de 283 cursos de especialização, 84 cursos de residência e 5 cursos de aperfeiçoamento. A população estudantil de pós-graduação é composta por 20.174 alunos, assim distribuídos: 1.459 alunos de mestrado profissional, 5.946 alunos de mestrado acadêmico, 6.788 alunos de doutorado, 4.943 alunos de especialização, 893 alunos de residência e 55 alunos de aperfeiçoamento.

No que tange aos seus servidores (professores, técnicos e terceirizados), ela dispõe de 13.664 pessoas, das quais 101 são professores da educação básica, 4.198 do magistério superior, 9.365 são técnicos e 2.518 são terceirizados. Juntando todos estes totais, chega-se ao significativo número populacional geral universitário de 70.725 pessoas.

Previstas constitucionalmente como autarquias, as universidades federais são definidas pela Constituição de 1988, que diz, em seu artigo 207, que

As universidades gozam de autonomia didático-científica, administrativa e de gestão financeira e patrimonial, e obedecerão ao princípio de indissociabilidade entre ensino, pesquisa e extensão.

Como toda instituição de ensino, a universidade aqui analisada é regulamentada pela já citada lei que estabelece as diretrizes e bases da educação nacional, cujas finalidades estão explicitadas em seu artigo 43, dentro da qual destacamos, para efeitos do presente artigo, a seguinte finalidade:

4 Dados obtidos do site da universidade. Disponível em: https://xn--graduao2wa9a.ufrj.br/images/_Nova_Estrutura/Pesquisa_Analise_Dados/Graduacao_em_Numeros__Bloco_I.pdf. Acesso em: 01 maio 2019.

${ }_{5}^{5}$ Dados levantados junto à Pró-reitoria de Pós-graduação e site da UFRJ, por meio da Coordenadoria de Comunicação da UFRJ, em 5 de maio de 2018. 
VI - Estimular o conhecimento dos problemas do mundo presente, em particular os nacionais e regionais, prestar serviços especializados à comunidade e estabelecer com esta uma relação de reciprocidade;

Em resumo, podemos dizer que, entre outras responsabilidades, cabe à universidade federal promover ações de ensino, pesquisa e extensão com outras instituições, particularmente em parceria com as escolas da educação básica e em benefício mútuo. Isto significa dizer que, justamente por serem realidades tão diferenciadas administrativamente, esta parceria dependeria, para dizermos o mínimo, de gestões competentes.

No que diz respeito aos interesses deste ensaio, elegemos a acessibilidade como tema articulador, ou seja, o tema por meio do qual pretendemos discutir de que forma a gestão de um e de outro tipo de instituição tem se comportado e que tipo de aprendizagens poderiam decorrer da troca de experiências entre ambas. Dado que já descrevemos o aspecto da acessibilidade na escola da educação básica que é foco deste artigo junto com a universidade também foco de nosso interesse, passaremos agora a descrever como se tem dado a organização da acessibilidade nesta última instituição.

\section{A questão da acessibilidade na universidade federal}

A preocupação com esta temática do modo como a conceituamos neste artigo sempre esteve presente na universidade aqui narrada, na atuação de grupos de ensino, de pesquisa e de extensão. No entanto, tais ações permaneceram, por muitas décadas, desarticuladas.

Em 2005, com o lançamento do Programa Incluir, iniciaram-se os primeiros esforços para a articulação dos referidos grupos, tendo em vista possibilitar a participação da universidade a concorrer ao Edital do Programa. Cerca de vinte grupos de pesquisa e extensão foram convidados a participarem desta movimentação, que culminou na criação, em 2007, de uma divisão de inclusão e acessibilidade vinculada à Pró-Reitoria de Graduação. Esta divisão perdurou por alguns anos, mas sendo liderada por apenas uma técnica e sem outros aportes da universidade. $\mathrm{O}$ orçamento obtido pela participação da referida universidade nos editais do Programa Incluir era o que garantia as ações de acessibilidade na universidade, e tal orçamento sempre ficou muito aquém das necessidades da universidade como um todo. 
Em 2015, nova tentativa se fez de articular tais grupos em uma grande iniciativa pró inclusão e acessibilidade na universidade. Desta vez, o movimento se organizou com maior contundência e este sucesso culminou na fundação do Fórum Permanente Universidade Acessível e Inclusiva (FPAI), em 20 de setembro de 2016. Este Fórum se reúne mensalmente, e uma de suas principais funções é construir as pautas relativas às questões de acessibilidade das pessoas com deficiência da comunidade universitária.

Também no ano de 2016 foi promulgada a Lei 13.409, de 28 de dezembro de 2016, que institui a reserva de vagas por ação afirmativa também para postulantes com deficiência ao ensino superior. Desnecessário dizer do imediato impacto que tal medida acarretou para as universidades públicas, e que nossa universidade não foi exceção. Chegara o momento, afinal, em que a presença de alunos com deficiências se faria de forma mais visível no cotidiano universitário.

Assim, ao longo de 2017, os participantes do FPAI discutiam de forma pungente como se faria a primeira seleção a partir da referida Lei, e como se organizaria para atender aos ordenamentos da mesma. Por este motivo e outras discussões que se davam durante o ano, os membros do FPAI foram percebendo que apenas construir as pautas e discuti-las não seria suficiente. Era preciso se garantir uma instância executiva voltada para a acessibilidade. Assim, como fruto da luta levada a cabo pelo Fórum em 2017, em 22 de fevereiro de 2018, a comunidade com deficiência da universidade, por meio do FPAI, conseguiu que o gabinete do reitor criasse uma nova Diretoria, uma instância executiva, vinculada diretamente à reitoria: a Diretoria de Acessibilidade - DIRAC, sobre a qual falaremos a seguir.

\section{A Diretoria de Acessibilidade - DIRAC: Ações que fazem a diferença}

Em sua Portaria, de número 1.319 de 22 de fevereiro de 2018, publicada no Boletim Extraordinário da universidade de no. 8 de 22 de fevereiro de 2018, a DIRAC foi criada com a finalidade de construir políticas institucionais de acessibilidade e inclusão, com foco na inclusão de pessoas com deficiência.

Neste sentido, podemos dizer que a DIRAC tem um papel tanto executivo quanto educativo. Executivo, no sentido de dar andamento às diretrizes desejadas pela Reitoria em termos de acessibilidade, assim como de dar encaminhamento às demandas de acessibilidade levadas à DIRAC pelo FPAI perante a gestão superior da universidade. O caráter educativo de suas ações reside no fato de que seria impossível 
uma administração central, sozinha, responsabilizar-se pela promoção da acessibilidade em uma instituição de tal monta. Ademais, sempre convém lembrar que inclusão é e deve ser assunto de todos, e não apenas de algumas instâncias institucionais ou estatais.

Desta maneira, a referida diretoria tem feito um trabalho incansável de visitas e orientações a todas as Unidades e Campi da universidade. Naquilo de técnico que lhe cabe, como por exemplo auxiliar as Unidades a (re)pensarem seus currículos e suas práticas pedagógicas, a DIRAC tem tido presença marcante. Sua atuação tem se dado em frentes variadas, e na esfera administrativa conseguiu concursar 12 servidores em 2018, que formam sua equipe técnica. Igualmente, tem se esforçado para garantir assento nos Colegiados Superiores da gestão universitária, bem como organizado o processo de análise de laudos quando da entrada de alunos com deficiência por cotas para pessoas com deficiência (PcD), entre muitas outras ações.

Aqui, são de se destacar as ações de respostas a processos que lhes são encaminhados por candidatos não aprovados em seus laudos como cotistas PcD. Tais processos vêm tanto do Ministério Público quanto da Defensoria Pública, e exigem respostas elaboradas para explicar o porquê das negativas. A este propósito, convém esclarecer que a maioria dos casos é aprovada, ficando 'de fora' aqueles cujos laudos não se enquadram nos termos dos Decretos 3.298 de 1999 e 5.296 de 2004, que regulamentam os tipos de deficiências aceitos como passíveis de cota para entrada na universidade.

Dos casos que a DIRAC recebe, relativos a recursos judiciais, o mais emblemático talvez seja o de candidatos surdos já aprovados como cotistas e que, ao entrarem para a universidade, têm se deparado com a falta de intérpretes que lhes acompanhem durante seu percurso acadêmico. Tais casos são emblemáticos por serem os que, até o presente, geraram a assinatura, por parte da universidade, de TAC (Termo de Ajuste de Conduta). Segundo Fontes (s/d),

O termo ou ajustamento de conduta é um modo pelo qual é dada ao autor do dano a oportunidade de cumprir as obrigações estabelecidas, comprometendo-se o ente legitimado, de sua parte, a não propor a ação civil pública ou a pôr-lhe fim, caso esta já esteja em andamento. [...]. Assim, desde que cumprido o ajuste, terá o compromisso alcançado seu objetivo, sem a necessidade de movimentar toda a máquina judiciária (p. 49).

O Termo assinado prevê a contratação por licitação, até julho de 2019, de 40 intérpretes de Libras pela universidade. Cabe ressaltar que a DIRAC vem tentando esta 
contratação desde muito antes de o TAC ter sido necessário: desde o início de 2018, quando entraram os primeiros surdos por cotas PcD. Estas tentativas não vinham obtendo sucesso, entre outros motivos, por conta da própria morosidade burocrática em que tal contratação por licitação implica.

Além disso, e talvez principalmente, os custos desta ação licitatória ultrapassaram o que a universidade tinha em seu orçamento. Ao final de 2018 tentou-se ampliar a previsão orçamentária da DIRAC para dar conta desta demanda, já imaginando-se que em breve um processo judicial se faria. No entanto, tendo em vista os contingenciamentos contínuos por que têm passado as universidades federais, não apenas a previsão não pôde ser ampliada, como ainda sofreu contingenciamento da ordem de $50 \%$.

O fato é que até o presente momento (maio de 2019), a despeito da assinatura do TAC, nenhuma contratação pôde ser feita. Em 30 de junho de 2019 se encerra a atual gestão e a pergunta que fica é: será possível efetivar a licitação antes disso? Caso não, como se comportará a próxima gestão? Este assunto também nos faz retomar uma de nossas preocupações: teria sido falta de empenho por parte da gestão da universidade?

Cremos, sinceramente, que não. Por meio de nosso olhar omnilético, podemos destacar, talvez, um pouco de desorganização pela inexperiência com o trabalho, outro tanto de ignorância sobre a premência legal da matéria, e outro tanto de obstáculos impostos pelo próprio sistema federal sejam alguns dos fatores que possamos levantar para analisarmos as causas desta lacuna. Mas não cremos haver falta de comprometimento, e isto pode ser provado pela concessão de algumas vagas de reserva da própria reitoria para cargos concursados de intérpretes e outros técnicos igualmente importantes para a promoção da acessibilidade.

\section{A escola de educação básica e a imensa universidade: dois cenários, muitas interseções}

No cenário brasileiro, a educação básica clama por atenção, em todos os níveis, mas principalmente no que diz respeito aos processos desencadeados por leis específicas sobre inclusão em educação. Contudo, mesmo este cenário de despreparo parece mais preparado quando se coloca em vista a educação superior. Historicamente, as escolas vêm trabalhando com alunos com deficiência, transtornos e mesmo dificuldades de aprendizagem há muito tempo, mas as universidades estavam, neste 
sentido, reservadas àqueles sem quaisquer problemas de aprendizagem, aos brancos, aos possuidores de condições para concluir um curso universitário.

$\mathrm{O}$ fato de estarem invisibilizados (quando presentes) ou ausentes da universidade, de serem minoria numérica ou de não experimentarem os processos educativos atravessados pelas deficiências ou por outros marcadores sociais e identitários usados como justificativas para a execução de processos discriminatórios que levam às variadas exclusões, distanciou as universidades das escolas, apesar de todas as pesquisas realizadas no campo da inclusão. A entrada de alunos com deficiência e de outros grupos excluídos ou invisibilizados no âmbito universitário, atualizou uma demanda premente de ressignificação da universidade, mais aberta, mais acessível.

O movimento de mudança, para cada espaço, seja numa escola específica ou numa imensa universidade, gera transformações físicas, estruturais e pessoais. Na escola foco de nossa análise, tal mudança passou pelo incômodo sentido por um grupo de professores, pelas dificuldades de aprendizagens apresentadas por diversos alunos, com risco iminente de jubilamento. Para a universidade em tela nesta análise, tais mudanças passaram pela necessidade legal de se "preparar" para o momento em que receberiam de fato os alunos com deficiência e demais cotistas.

Desde 1990, o início das discussões sociais sobre o movimento de inclusão, até 22 de fevereiro de 2018, com a criação da DIRAC, passaram-se 28 anos. Preciosos anos para aqueles alunos que sonhavam cursar o ensino superior. Antes tarde do que nunca, já dizia o ditado popular. Contudo, este espaço de tempo parece ter colocado a escola no papel de ensinar, com base em sua vasta experiência, ao gigante caminhar.

Analisando os dois processos de adaptação para uma educação promotora de inclusão, percebemos pontos extremamente positivos, mas também pontos que necessitam de maiores reflexões. Com relação ao colégio, consideramos o momento de ruptura com a educação vigente, aquele do incômodo sentido por um grupo de professores quando da reprovação dos alunos com dificuldades de aprendizagem. Por outro lado, acreditamos que a criação de turmas específicas coloca a escola no modelo daquelas que adotavam as classes especiais como alternativa para a educação de alunos com transtornos ou deficiências.

Com relação à universidade, o Programa Incluir, em 2005, foi o disparador das discussões sobre acessibilidade. Tais discussões passavam pela análise dos espaços como rotas de acesso, bibliotecas, salas de aula inacessíveis para alguém com 
dificuldade de locomoção, ou mesmo cadeirantes. Neste espaço, a questão da acessibilidade foi o gatilho para as discussões iniciais. Neste sentido, considerando que na escola o ponto detonador do movimento por transformações em prol da inclusão se deu com a reprovação e posterior jubilamento de alunos, na universidade, as questões sobre a acessibilidade foram priorizadas. Isto significa que a escola já era acessível? Ou que a universidade já teria as estratégias didáticas para educar e formar o aluno com deficiência?

Para as duas perguntas a resposta é não necessariamente, pois se para a escola a questão pedagógica falou mais alto, isto pode ter acontecido por causa dos anos de experiência com alunos com diversas condições e das alternativas adotadas ao longo desses anos para sanar as barreiras cotidianas. Para a universidade, datadas do início do século XX, com muitos de seus prédios tombados pelo Patrimônio Histórico e Cultural e sofrendo com parcos e esparsos financiamentos públicos, a questão da acessibilidade pareceu urgente.

Em que pese os motivadores das mudanças, a escola e a universidade fizeram escolhas consistentes. No caso da escola, a sensibilização dos professores para a história familiar dos alunos do projeto, o olhar apurado da orientadora pedagógica para todo o processo de aprendizagem dos alunos, e mesmo a flexibilização do tempo de aprendizagem foram fundamentais para a consolidação do projeto alinhado aos princípios da inclusão em educação.

No caso da universidade, as mudanças estruturais baseadas na criação e manutenção de grupos de discussão ligados à reitoria, davam sentido e corpo às mudanças que viriam. Neste sentido, a universidade seguiu coerente à lógica acadêmica. Segundo Marx (1867), “o pior dos arquitetos difere da mais hábil das abelhas, pelo fato de que, antes de fazer uma caixa de madeira, ele já a construiu mentalmente" (apud VYGOTSKY, 2003, p.7). Em outras palavras, procurou pensar, articular, desenvolverse conceitualmente antes que se partisse para o ato, neste caso, o de receber, educar e formar, efetivamente, os alunos com deficiência.

Tais caminhos levaram a escola e a universidade a um momento peculiar de complementaridade, no qual de um lado o convívio com alunos com diversas condições físicas, psíquicas, cognitivas e sociais oportunizaram as escolas a desenvolverem estratégias que extrapolavam o processo ensino-aprendizagem ao ameaçarem as relações sociais como as diversas faces do bullying, da depressão infanto-juvenil, do 
suicídio. Outros aspectos também foram encarados com coragem pelas escolas como as questões de gênero.

Do lado da universidade, relações de parcerias desde sempre foram estabelecidas com as escolas por meio dos grupos de pesquisas. Estes estudos, baseados nas instituições escolares, refletiram e continuam a refletir, muitas vezes em colaboração, alunos, professores e pesquisadores, os fundamentos de um saber acadêmico sobre a relação ensino-aprendizagem, que formam um arcabouço conceitual e prático para a efetivação do ato de educar no âmbito da universidade.

Ainda que, no campo da inclusão, a experiência da universidade seja mais conceitual do que prática, a criação de instâncias institucionais voltadas para a defesa da inclusão e permanência do aluno com deficiência no espaço acadêmico, oferece um panorama concreto e mais seguro de efetivação de ações para a inclusão nas escolas. $\mathrm{O}$ que se percebe é que, ambas, escola e universidade, têm muito o que ensinar e muito o que aprender uma com a outra. A troca de experiências e informações parece fundamental para o desenvolvimento de culturas, políticas e práticas de inclusão em educação.

\section{Considerações finais}

Iniciamos o presente artigo refletindo sobre os avanços e desafios ainda presentes no que tange à promoção de inclusão e acessibilidade na Educação Superior e na Educação Básica. Lançamos algumas questões para reflexão: que interseções podem ser traçadas entre os casos aqui mencionados? Qual seria a relevância de se levar a cabo tal empreitada? O que tais interseções poderiam nos ensinar, se identificadas, em termos de promoção de inclusão e de acessibilidade? Nossa hipótese central era de que a gestão comprometida com inclusão e acessibilidade faria a diferença.

São muitas, e desejáveis, as interseções possíveis entre escola e universidade. A principal delas, em nossa percepção, reside na troca possível e mesmo numa eventual troca de papéis, em que as escolas, com sua experiência material e antiga de inclusão e acessibilidade, possa ensinar a universidade no que tange à sua necessária adaptação aos novos tempos. Em contrapartida, a universidade pode - deve! -, com seus saberes e arcabouços conceituais, fortificar os fazeres da escola no sentido de os tornar mais criativos e empoderados no que tange à busca de soluções de problema de exclusão e falta de acessibilidade. 
De nossos apontamentos acerca dos dois casos aqui narrados, deduzimos - e defendemos - que há muito que se aprender (universidade e escola) mutuamente, e isso é possível quando a gestão está, ainda que com todas as dificuldades políticas e materiais, verdadeiramente comprometida com o avanço em relação ao desenvolvimento de culturas, políticas e práticas de inclusão em seus cotidianos. No que tange às instituições aqui enfocadas, a materialização disto se dá em um projeto de parceria atualmente em andamento, que envolve o comprometimento de ambas as gestões, o que nos deixa muito gratificadas e esperançosas.

\section{AGRADECIMENTOS: CNPq, CAPES}

\section{REFERÊNCIAS}

BOOTH, T.; AINSCOW, M. Index para a Inclusão: desenvolvendo a aprendizagem e a participação nas escolas. Londres, CSIE, 2002.

BOOTH, T.; AINSCOW, M. Index para a Inclusão: desenvolvendo a aprendizagem e a participação nas escolas. Londres, CSIE, 2006.

BOOTH, T.; AINSCOW, M. Index para a Inclusão: desenvolvendo a aprendizagem e a participação nas escolas. Londres, CSIE, 2012.

BOOTH, T.; AINSCOW, M. Index para a Inclusão: desenvolvendo a aprendizagem e a participação nas escolas. Londres, CSIE, 2016.

BRASIL. Decreto 3298 de 20 de dezembro de 1999 - Regulamenta a Lei no 7.853, de 24 de outubro de 1989, dispõe sobre a Política Nacional para a Integração da Pessoa Portadora de Deficiência, consolida as normas de proteção, e dá outras providências. Brasília: Ministério da Educação, 1999.

BRASIL. Decreto 5296 de 02 de dezembro de 2004 - Regulamenta as Leis nos 10.048, de 8 de novembro de 2000. Brasília: Ministério da Educação, 2004.

BRASIL. Lei 13.409, de 28 de dezembro de 2016 - Altera a Lei $\mathrm{n}^{\circ} 12.711$, de 29 de agosto de 2012, para dispor sobre a reserva de vagas para pessoas com deficiência. Brasília: Ministério da Educação, 2016.

BRASIL. Lei 9394 de 20 de dezembro de 1996 - Estabelece as Diretrizes e Bases da Educação Nacional. Brasília: Ministério da Educação, 1994.

BRASIL. Lei $\mathbf{N}^{\circ} \mathbf{1 3 . 0 0 5}$ de 25 de junho de 2014 - Aprova o Plano Nacional de Educação - PNE e dá outras providências. Brasília: Ministério da Educação, 2014 
BRASIL. Programa Incluir. Brasília: Ministério da Educação, 2005. Disponível em: http://portal.mec.gov.br/programa-incluir. Acesso em: 05 maio 2019.

BRASIL. Ministério da Aeronáutica. Parecer CFE 829/81.Disponível em: http://www2.fab.mil.br/cbnb/images/regimes/regimesub.PDF. Acesso em: 19maio 2019.

FONTES, M. C. G. Compromisso de ajustamento de conduta. Revista Jurídica da UniFil, ano IV, n. 4, p. 49.

LIMA, C. B.; SOUZA, J. M. P. Autoestima e aprendizagem: reflexões sobre uma prática inclusiva. Cap. 14. In Filosofia, Política, Educação, Direito e Sociedade 2. Organizadora Solange Aparecida de Souza Monteiro. Atena Editora: 2019.

LUKÁCS, G. Para uma ontologia do ser social. Boitempo editorial, 2015.

MENEGHETTI, F. K. O que é um Ensaio-Teórico? RAC, Curitiba, v. 15, n. 2, p. 320332, mar./abr. 2011. Disponível em: www.anpad.org.br/rac. Acesso em: 20 maio 2019.

MORIN, E. Introdução ao Pensamento Complexo. Tradução de Dulce Matos. 5. ed. Lisboa: Instituto Piaget, 2008.

SANTOS, M. P. dos. Dialogando sobre inclusão em educação: contando casos (e descasos). Curitiba: CRV, 2013.

UNESCO. Declaração Mundial de Educação Superior. Paris: UNESCO, 1998

UNESCO. Declaração Mundial sobre Educação para Todos. Paris: UNESCO, 1990

UNIVERSIDADE FEDERAL DO RIO DE JANEIRO. Portaria $\mathbf{N}^{\circ} 10264$ de 18 de novembro de 2016. Cria a Comissão Executiva Provisória Forum UFRJ Acessível e lnclusiva-FPAI). UFRJ, 2016.

UNIVERSIDADE FEDERAL DO RIO DE JANEIRO. Portaria $\mathbf{N}^{\circ} 1319$ de 22 de fevereiro de 2018. Cria e nomeia a Diretoria de Acessibilidade (DIRAC), vinculada ao Gabinete do Reitor. UFRJ, 2018.

VYGOTSKY, L. S. A formação social da mente. São Paulo: Martins Fontes, 1998. 


\section{Como referenciar este artigo}

SANTOS, Mônica Pereira dos; MELO, Sandra Cordeiro. Interseções na gestão da acessibilidade na educação básica e no ensino superior: um ensaio omnilético. Revista on line de Política e Gestão Educacional, Araraquara, v. 23, n. esp. 1, p. 818-835, out. 2019. E-ISSN:1519-9029. DOI: https://doi.org/10.22633/rpge.v23iesp.1.13008

Submetido em: 10/05/2019

Revisões requeridas: $14 / 06 / 2019$

Aprovado em: 10/08/2019

Publicado em: 01/10/2019 